\title{
Correction to: Unequal bodies: corporeality and social inequality in mathematics classrooms
}

\author{
Nina Bohlmann ${ }^{1}$
}

Published online: 12 December 2018

(c) FIZ Karlsruhe 2018

\section{Correction to: ZDM}

https://doi.org/10.1007/s11858-018-1005-6

In the Abstract a reference has been duplicated by error. The correct Abstract is shown below.

The original article has been corrected.

\begin{abstract}
This paper addresses teachers' corporeality and its influence on the structuring of mathematics classroom interaction. The present contribution explores the way a teacher's bodily activity is implicated in the (re)production of social inequality, and challenges the assumption that the teaching and learning of mathematics is primarily a linguistic and semiotic accomplishment. I argue that the teacher's body is an active force in the formation of mathematically 'able'
\end{abstract}

and 'less able' students. Drawing on the work of Bernstein (Pedagogy, symbolic control, and identity: Theory, research, critique (Revised Edition), Rowman \& Littlefield, Lanham, 2000) and his sociological theory of pedagogy, and expanding his tools to address corporeal factors, I show how students are positioned as high-performing within structures of classroom interaction. Video data from classroom interaction is used to track differences in how teachers reveal and conceal structural peculiarities of school mathematics. Comparing the interaction of different teachers illustrates the role that corporeality plays in establishing distinctive orientations to meaning-making in the mathematics classroom.

The original article can be found online at https://doi.org/10.1007/ s11858-018-1005-6.

Nina Bohlmann

nina.bohlmann@uni-leipzig.de

1 Faculty of Education, Leipzig University, Marschnerstraße

31, 04109 Leipzig, Germany 